\title{
REDES DE TRANSPORTE Y COMERCIALIZACIÓN DE LA INDUSTRIA PAÑERA RIOJANA EN LA SEGUNDA MITAD DEL SIGLO XIX
}

\author{
Joaquín Giró*
}

Dice el refrán que "el buen paño en el arca se vende", y es posible que parte del paño consumido en las localidades riojanas, se adquiriera por conocimiento personal de aquellos artesanos tejedores, que en ocasiones hacían funciones de sastre, para adquirir el género necesario para su vestuario; aunque dada la envergadura de la producción fabril, ésta, necesariamente buscó de siempre', otros mercados que los provinciales.

El sistema que se utilizaba para salir a vender fuera de la provincia era el de la arriería o el de la venta ambulante, en ambos casos, dados los problemas de transporte por las condiciones del firme de los caminos, o la inexistencia de los mismos, se buscaba el apoyo de animales de tiro y carga:

"Los medios de transporte se basan en la utilización de bueyes y caballos, y las mulas, usándose las últimas indistintamente como animales de tiro y carga. Las abultadas cifras de animales de estas especies se mantendrán sin alteración sensible hasta muy avanzado el siglo, para caer las dos últimas rápidamente debido a la competencia del ferrocarril. Los bueyes se utilizan uncidos por parejas a las lanzàs de las carretas, vehículos de dos ruedas sin herrar que pueden transportar hasta 40 arrobas $(460 \mathrm{Kgs}$.) y que habitualmente

* Universidad de La Rioja.

1. "Las fábricas de Soto de Camero Viejo, que tenían despacho en sus domicilios y sus géneros eran adquiridos, unos por los naturales para vestirse, y los más para venderlos -como los Ilevaban los comerciantes y tratantes de esta villa y sus contornos- a la ribera, Montañas de Burgos, Vizcaya, Galicia, Tierra de Campos, Madrid y los cuatro Reinos de Andalucía, la Mancha, Provincia de Extremadura y Reino de Navarra, en algunas ocasiones también se fabricó para embarcar a Indias". Ochagavía, D. "Historia textil riojana", Logroño 1957, pp. 96 y 97.

2. Artola, M. "La burguesía revolucionaria", Madrid 1974, pp. 94 y 95. 
marchan agrupados formando carreterías de 20 a 30 unidades. Las mulas se utilizan para arrastrar vehículos de tres tipos básicos: calesas de dos ruedas y varas, coches de colleras de cuatro ruedas, y galeras, más pesadas que los anteriores y generalmente cubiertas, que cargan hasta 120 arrobas. Alternativamente son utilizadas como animales de carga formando recuas que dirigen los arrieros".

Efectivamente los medios de transporte que utilizarán los arrieros y fabricantes para el transporte de sus géneros, serán las galeras y las recuas de mulas, pues el ferrocarril ${ }^{3}$ no toma consistencia como transporte hasta finales del XIX. Al respecto es significativo el gran número de animales de esta especie, con que cuenta la provincia de Logroño en 1876: 16.808 animales. El ganado vacuno que cuenta 8.821 animales, o el caballar con 8.077 y el asnal con 11.366, es menos significativo, puesto que desconocemos el número de tales que se empleaban para el transporte o si formaban parte de las cabañas ganaderas para su explotación agrícola o alimentaria.

Hay numerosos testimonios ${ }^{4}$ que indican que el transporte con mulas era usual para los intercambios comerciales, pues si bien los arrieros salían de los pueblos fabriles con paños, chocolates, vino, aceite y cuantos productos se elaboraban en el lugar, volvían igualmente cargados con otros productos básicos, mercancías diversas e incluso viajeros. También hacían de correo, al transmitir recados y mensajes a las personas que visitaban por los pueblos que atravesaban, en su largo trayecto hasta el punto de destino, que muchas veces se situaba en los extremos norte (Galicia) y sur del país (Andalucía).

Un testimonio de viejos arrieros de Enciso nos indicaba que un primer destino de los paños era Medina del Campo donde se encontraban los almacenes, para seguir camino hasta Galicia. Durante el trayecto iban deshaciéndose de la carga de paños y las mulas. Estas ventas de paños a lo largo de las numerosas localidades que recorrían durante el trayecto, serían principalmente las de los pequeños fabricantes y artesanos, los cuales confiarían al arriero su pronta ven-

3. "Los medios de locomoción eran varios; además del tren, que se inauguró el año 1863, se empleaban, desde los sufridos rucios, hasta las desvencijadas diligencias tiradas por caballos, que hacían el recorrido hasta la Sierra de Soria". Gutiérrez Achútegui, "Calahorra d'antaño", Logroño 1964, p. 1.

4. "Los vinos de Aranda y de Peñafiel competían con los de La Rioja en la ciudad de Burgos y en las montañas de la provincia, y es probable que también fueran consumidos en las zonas cercanas a la cordillera Ibérica. Estos vinos, transportados por los arrieros de los pueblos de las montañas dedicados a la arriería como solución ante la falta de recursos en las tierras pobres, daban lugar a un comercio activo entre las zonas de montaña y las de llanura. Los arrieros descendían anualmente a las llanuras castellanas con aperos, ruedas, duelas para trillos, ganado de labor y lino que cambiaban por trigo y por vino para el consumo en las zonas deficitarias. El transporte se hacía en carros y cuando los caminos no lo permitían, a lomo de mulas". Gonzalo Anes, "El Antiguo Regimen: Los Borbones", en Vol V de "Historia de España". Artola, M. (dir.), Madrid 1973, pag. 175. 
ta, precio y margen de beneficio, dejando para los almacenes y sociedades comerciales los paños de los industriales. A la vuelta, el mismo arriero iría adquiriendo otros productos demandados por el mercado doméstico, junto a las mulas que había dejado a lo largo del camino de ida.

Un itinerario más local, dada la proximidad entre las localidades, era el que tomaban algunos arrieros de Enciso con sus caballerías cargadas de paños, de donde salían por la mañana para pernoctar en la Venta Rufino (empalme Alcanadre-Corera), para continuar al día siguiente hasta Logroño, donde adquirían vino y otras mercancías. Otro itinerario era el que les llevaba hasta la localidad aragonesa de Tarazona, pasando por las sorianas de Yanguas y San Pedro Manrique. Al respecto no hay que olvidar que la mayor parte de los matrimonios efectuados en Enciso durante este siglo con personas forasteras proceden principalmente de estas localidades sorianas.

Otras localidades de donde ha salido gran número de arrieros han sido Ortigosa y Soto en los Cameros, Arnedo en el Cidacos y Cervera en el Alhama. De todas ellas podemos citar numerosos testimonios acerca de los modos de vida de sus poblaciones, de las que siempre encontramos la alternancia entre las labores del campo u otras, con la arriería, que les lleva de lugar en lugar y de feria en feria, por toda la geografía española.

En Aguilar del río Alhama, el comerciante Domingo Mayor, hermano de los fabricantes de lienzos "Ruiz Hermanos y Sáinz", Ilega en 1874 al siguiente acuerdo con un arriero o trajinante, el cual declara ante el notario ${ }^{5}$ que ha recibido de la casa comercio de Domingo, en diferentes épocas y para su venta, géneros de lencería, sobre lo cual unas veces pagaba y otras entregaba varias cantidades dando por resultado un alcance a favor del Domingo de 744,40 ptas., y que careciendo de metálico, ofrece pagarlo mediante todo el trigo y cebada que se recolecte en la cosecha próxima en las tierras que lleva en colonia de Anacleta Fernández Vizmanos, a excepción de 10 medidas de trigo que es la renta que debe entregar, siendo de cuenta del Agapito los trabajos de recolección y demás. Además, 175 ptas. que deben varias personas procedentes de géneros de lencería que se compromete a entregar en metálico en término de cuatro meses, y la diferencia que resulte se compromete a entregar a medida que sus facultades se lo permitan.

Como se puede observar, la profesión de ambulante viene obligada por la necesidad al no poseer tierras de labrantío, pero además, esta profesión tan sólo le sirve para endeudarse, pues no logra sacar los beneficios necesarios para cubrir su subsistencia, utilizando los géneros en préstamo a modo de crédito sin interés, aunque en otras ocasiones, Domingo les obliga a escriturar una obligación hipotecaria con el $6 \%$ de interés.

5.AHP La Rioja/Protocolos/Portilla, J.M./Sign.6188/P-52, FF.174-175. 
Este oficio de transportista a lomos de mulas y caballerías, es compatible con el mal estado de las comunicaciones y la escasa infraestructura viaria y de transporte. En 1866 se constituye ${ }^{6}$ una sociedad para el servicio de carruajes de Haro a Ezcaray y viceversa. La componen por una parte, Agustín Ruiz Palacios y Santiago Calvo Martínez (vecinos de Haro), Leandro Arce Mayor (vecino de Santo Domingo) y Tomás Pérez Robredo (de Ezcaray), y por la otra Antonio Díez Bernal, cochero y Patricio Díez Zapatero, mesonero, ambos vecinos de Haro.

Ya tenían establecido el servicio con anterioridad, hasta que en febrero decidieron montar la sociedad y comenzarla en marzo, bajo las siguientes condiciones: Todos los días saldrá desde la villa de Ezcaray, a las seis de la mañana, un carruaje que contendrá tres asientos de berlina, seis de interior y cuatro de imperial cupé, pasando por Santo Domingo y deteniéndose todo el tiempo necesario para dejar y tomar los asientos que queden y salgan de la Ciudad; $y$ continuando su marcha llegará a Haro, desde cuyo punto saldrá otro carruaje todos los días a las tres y media de la tarde, de la misma forma y número de asientos del anterior. Que para el buen desempeño del servicio se engancharán en los carruajes el número suficiente de caballerías, siendo de precisa obligación el no emplear desde Haro hasta Santo Domingo más tiempo que dos horas y media y menos si fuese necesario; y desde Santo Domingo a Ezcaray una $y$ media; y a la vuelta desde Ezcaray a Santo Domingo, 5/4 de hora, y de Santo Domingo a Haro, dos horas.

El coche que vaya de Ezcaray a Haro tomará los tiros de Palacios y Calvo y el que salga por la tarde de Haro tomará los tiros de Antonio y Patricio. Que como el servicio de Santo Domingo a Ezcaray corresponde hacerlo por mitad entre los cuatro primeros socios de una parte y los dos segundos de la otra, se ha convenido verificarlo todos los días el Tomás Pérez, poniendo este el número suficiente de caballerías, abonando el Antonio y el Patricio por una parte 400 rs. mensuales y el Leandro 200 rs. por otra, al Pérez por este servicio. Que como las valijas de la correspondencia se hallan rematadas por otro y éste pondrá a un apersona de su confianza para distribuirla, la conducción de dichas valijas será de carácter gratuito, pero la persona de confianza actuará de mayoral de los carruajes sin que pueda pedir ningún sueldo a los socios.

Así pues, los servicios de diligencia serán el medio de transporte habitual hasta que la llegada del ferrocarril y los vehículos a motor comiencen a desplazar a las caballerías, aunque estos cambios habrán de esperar a finales de siglo.

Sin embargo, no siempre aparecían personas emprendedoras que establecieran el servicio de diligencia, o que se hicieran cargo de servicios parecidos. Este es el caso de la subasta en 1879, del servicio de conducción diaria del correo, entre la estación de ferrocarril de Castejón y la localidad de Cervera,

6. AHP La Rioja/Protocolos/Santa María/Sign.8148/P-79, FF.466-469. 
pasando por las navarras de Fitero, Cintruénigo y Corella, que finalmente quedó desierta.

Estos servicios de transporte de personas, correos y mercancías tenían una dificultad insoslayable cual eran las carreteras provinciales. La Diputación, desde que se creó la provincia de Logroño, va a llevar a cabo como cometido principal, la creación, estudio, construcción y conservación de las denominadas carreteras provinciales. Normas ${ }^{7}$ como la instrucción de 18 de marzo de 1852 de la Sección de Fomento de la provincia, que establecía los términos de cómo hacer públicas las subastas, los pliegos de condiciones facultativas y económicas, etc., fijaban, incluso las condiciones de la puja mínima para la licitación.

A tal efecto los miembros de la burguesía industrial no fueron ajenos a las posibilidades de negocio que les ofrecía estas actividades constructivas de carreteras, máxime cuando ellos, además, estaban sumamente interesados en mejorar las comunicaciones de sus localidades fabriles, con el fin de entrar en los circuitos modernos de transporte de personas y mercancías.

Por ejemplo, el fabricante de Ortigosa, Esteban de la Riva, contando 25 años, logra hacerse en $1860^{8}$ con la adjudicación para la ejecución de las obras de la carretera de tercer orden de Villanueva a Ortigosa por la cantidad de 63.157 ptas.; a tal efecto apodera ${ }^{9}$ a Francisco Sáenz Díez y Labiano, vecino de Madrid pero natural de Torrecilla de Cameros, para que formalice fianza y cuantas obligaciones del remate se deriven. Además, apodera al banquero Pedro Ramos, y a los fabricantes Jacinto Sáenz Díez y Eusebio de la Riva, vecinos de Logroño el primero y de Ortigosa los otros dos, para que le representen en cuantos negocios le ocurran como tal rematante de las obras. Finalmente, unos meses después, Esteban de la Riva constituye sociedad ${ }^{10}$ con dos vecinos de Mondragón y otros dos de Pradillo y Villanueva, para la realización de la carretera. El negocio para Esteban, proviene de la condición establecida al finalizar las obras, en que se estipula que la mitad de los beneficios serán para Esteban y la otra mitad para los otros cuatro.

En 1864 se inician los trabajos de ejecución de la carretera de Arnedillo a Enciso y, en 1866, la carretera de acceso a Munilla, cuya ejecución previa

7. Bermejo, F. y Delgado, J.M. “La Administración provincial española. La Diputación provincial de La Rioja". Logroño 1989, pag. 511.

8. "La afluencia de dinero remitido por los familiares ausentes hace que Ortigosa sienta de nuevo el bienestar y alegría perdidos en años aciagos. Se fomenta la instrucción, hasta conseguir desterrar el analfabetismo; los maestros, bien pagados (5.500 rs pagaba el municipio en 1842) y considerados, se exceden en su misión de enseñar; se mejoran los servicios de toda índole; hacia 1860 se inicia, y después se lleva a cabo, la traída de aguas abundantes y sanas que surten a tres fuentes públicas, se construye la carretera que une al pueblo con la de Soria a Logroño y comienza la explotación ordenada de la madera de sus bosques". Martínez Olmedo, L. "Monografía de la villa de Ortigosa de Cameros", Madrid 1946, pag. 33.

9. AHP La Rioja/Protocolos/Castells y Navarro/Sign.6918, FF.69-73.

10. AHP La Rioja/Protocolos/Castells y Navarro/Sign.6918, FF.135-138. 
subasta, había recaído en el fabricante Juan Sáenz Domínguez, tal y como lo atestigua el acuerdo" de sus herederos, cuando en 1869, toman en consideración el compromiso de su padre para la construcción de la carretera, por lo que dejan en manos de uno de ellos 750 ptas., para atender a las responsabilidades que la Villa les exija.

Incluso el trazado de la carretera va a incidir en los negocios de dichos fabricantes, pues no sólo evalúan el costo de los caminos o accesos a dicha carretera desde sus instalaciones, sino que en ocasiones tienen en cuenta la posible venta de terrenos o edificios para la ejecución de las obras, y los perjuicios que se pueden derivar de su construcción. Así se pronuncia en 1864 el fabricante de Enciso, Juan José Gutiérrez, al arrendar' ${ }^{12}$ una fábrica de hilados al también fabricante Casimiro Mendiola, estableciendo que si por los trabajos de la carretera se paraliza la fábrica, Juan José abonará el importe de la venta correspondiente al tiempo que estuviera paralizada, como igualmente los perjuicios que dicha paralización les causare, y fuesen indemnizados por el Gobierno.

Sin embargo el desarrollo de tales obras debió tener un carácter limitado, hasta que se estableció el Plan General de 1880, por el que se determinaban las carreteras construidas, y las que debían construirse por orden de preferencia. Tras pasar por la Comisión de Fomento de la Diputación riojana, fueron aprobadas en sesión de 30 de abril de 1886, las carreteras de la general de Soria a Ortigosa en la plaza del pueblo; la de Autol con Alfaro; la de Alfaro con la estación de ferrocarril de Castejón, y la que partiendo del Hospital de Anguiano se unía al Monasterio de Valvanera.

Precisamente en 1886, cuando se lleva a cabo el escrutinio ${ }^{13}$ de votos en el colegio electoral de Ezcaray, para la elección de Diputado a Cortes, uno de los ciento cuarenta y dos electores con derecho a voto, el fabricante de lanas torcidas, Balbino Abad Hoyuelos, "protesta contra los votos emitidos por los electores en favor de Eduardo Peralta y Méndez (el cual resultó ganador), los cuales han sido dados bajo la presión de un acuerdo tomado en una reunión electoral en la que concurrieron el Ayuntamiento y demás vecinos electores, conviniendo prestar sus sufragios al candidato que más dinero diera para la instalación del Telégrafo y construcción de una Carretera a enlazar con la de Pradoluengo; lo cual es público y notorio han ofrecido Eduardo Peralta y sus agentes, y por tal motivo le han dado sus sufragios los electores del pueblo de Ezcaray, Valgañón y Zorraquín; y solicita por quien corresponda, se declaren en su día nulos y de ningún valor los votos emitidos".

Por lo que se deduce que la construcción de carreteras no es sólo una prerrogativa económica de los más poderosos, sino principalmente política, capaz

11. AHP La Rioja/Protocolos/Pedro Moreno/Sign.5749/P-1, FF.1-6.

12. AHP La Rioja/Protocolos/Pedro Moreno/Sign.5748/P-62, FF.204-205.

13. AHP La Rioja/Protocolos/Felipe/Sign.8696/P-36, FF.154-158. 
de mover los escasos votos de un electorado restringido a la burguesía propietaria, comercial e industrial.

El valor de las obras públicas llega incluso a las Cortes ${ }^{14}$ donde se seguirán debatiendo algunos aspectos relacionados con la mejora de las comunicaciones, principal campo de batalla en la liza electoral. Así, el diputado riojano Sr. Rodrigáñez, presentará un expediente en 1882 sobre los puntos donde deben concluir algunas de las carreteras de la provincia riojana; o el diputado don Práxedes Mateo Sagasta, que solicitará que se acepte como proposición de Ley en 1885, que la carretera de Logroño a Puente de Fonsaladra, sea declarada a cargo del Estado dado su interés de ruta nacional. El diputado Sr. Salvador solicitó en 1891, la inclusión de las de Treviana y Zarratón con la que iba de Logroño a Cabañas de Virtus, y la de Bañares con la que va de Haro a Ezcaray; los también diputados Groizar y Rodrigáñez, pedían en 1893 la inclusión de la municipal que unía las carreteras de Logroño a Zaragoza y de Arnedo a Estella; de nuevo el Sr. Tirso Rodrigáñez, en 1899 pide la inclusión de otras varias en el plan general.

$Y$ si bien todos estos proyecto viarios mejoraban o creaban la infraestructura de carreteras de La Rioja, el principal medio de transporte de viajeros y mercancías a finales de siglo será el ferrocarril. Hacia él dirigirán algunos esfuerzos inversores los hombres más pudientes de la burguesía riojana, tal y como se certifica en algunos inventarios post mortem donde aparecen los capitales invertidos. Por ejemplo, en el inventario ${ }^{15}$ de una de las mayores fortunas de la burguesía industrial, Teresa Alonso Gutierrez (Enciso, 1878), se declaran hasta 17.110 ptas. en obligaciones de ferrocarriles; otro ejemplo es el rico ganadero Isidro Fraile y Sáenz de Tejada (Torrecilla, 1883), en el que tasan ${ }^{16} 38.700$ ptas. en un resguardo de la caja de Depósitos, de cien obligaciones de Ferrocarriles, importantes 50.000 ptas. nominales, cuyos intereses están pagados sólo hasta el segundo semestre, inclusive de mil ochocientos setenta y siete: las obligaciones al $58 \%$, y a noventa y siete los intereses.

También de la misma zona, Jose María Sáenz de Tejada ${ }^{17}$, rico propietario de Almarza y Ribavellosa, localidades próximas a Torrecilla de Cameros (1885), manifiesta poseer hasta 5.000 ptas. en obligaciones del ferrocarril Tudela-Bilbao. Ya en la zona del Cidacos (Enciso, 1886), la mujer del fabricante Cándido de la Riva, Filomena Ruiz Alonso declara ${ }^{18}$ entre sus bienes $4.292,50$ ptas. en obligaciones de ferrocarriles.

No obstante estos intereses inversores de la burguesía industrial, y para desgracia de los fabricantes de la segunda mitad del XIX, las líneas de ferrocarril

14. Bermejo, F. y Delgado, J.M. "La Administración..." pp. 512-513.

15. AHP La Rioja/Protocolos/Pedro Moreno/Sign.8710/P-32.

16. AHP La Rioja/Protocolos/Castells y Navarro/Sign.6970/P-128.

17. AHP La Rioja/Protocolos/Castells y Navarro/Sign.8468/P-151.

18. AHP La Rioja/Protocolos/Pedro Moreno/Sign.8717/P-117. 
quedarán alejadas de las localidades industriales donde tenían sus establecimientos, tan sólo las cabeceras de Logroño, Calahorra y Haro se beneficiarán de este medio de transporte.

Pese a que el ingeniero Echanove presenta el primer proyecto de ferrocarril para La Rioja en 1798, que enlazaba Haro con Logroño, y que fue aprobado por los municipios riojanos que comprendía la Real Sociedad Económica de Cosecheros, la invasión napoleónica y otras circunstancias como el cólera de 1834, o las sucesivas guerras carlistas impidieron que dicho proyecto se llevara a cabo. Cuando por fin se inaugura el trazado Madrid-Irún ${ }^{19}$, la ciudad de Haro pierde la opción a convertirse en el principal centro ferroviario (al cruzarse con la línea Bilbao-Tudela que también pertenecía a la Compañía del Norte), en beneficio de la burgalesa ciudad de Miranda de Ebro. Sin embargo, otros proyectos queridos por los industriales de las localidades serranas sí saldrían adelante; este es el caso del ferrocarril Haro-Ezcaray inaugurado a principios de siglo y que permaneció en activo hasta los años sesenta de nuestro siglo; o el Calahorra-Arnedo-Arnedillo inaugurado igualmente a principios de siglo, impulsado gracias al carbón de lignito de las minas de Préjano.

Hasta que este último no se inauguró, los industriales de la cuenca del Cidacos debían trasladar sus géneros en galeras hasta la estación de Calahorra. Este es el caso del fabricante de Munilla, Mateo Enciso, socio de "Esteban Enciso e Hijos", el cual escritura en 1872 ante al notario $^{20}$, que teniendo dicha sociedad cinco fardos de paños depositados en la estación de ferrocarril de Calahorra, autorizan a Juan Juyarres de Calahorra, para que recoja dichos fardos devueltos por la Aduana de Irún, con la exención de derechos que indebidamente se les carga, mediante ser géneros españoles no sujetos a pago alguno, gestionando al efecto ante las corporaciones, oficinas y tribunales del Estado como procediere... , lo que nos indica algo acerca de las vías de comercialización que utilizan y los beneficios de que hacen uso.

En 1875 es la sociedad de fabricantes de Munilla, "Fernández Hermanos", los que son apoderados ${ }^{21}$ por los señores Massó, Carrillo, San Román y Cía,

19. "El cambio radical que el ferrocarril significó sólo se manifiesta en comparación con la situación precedente. La velocidad dio un salto desde los $8 / 10 \mathrm{Km} / \mathrm{hora}$ de la diligencia, a los 34 del exprés que unía Madrid a Hendaya en 1868, y aún fue más acusado el cambio en el número de personas transportadas, desde la docena o poco más de viajeros que llevaba una diligencia al centenar largo que podía acomodarse en el menor de los trenes. El transporte de mercancías experimentó un cambio semejante. Desde 1855 los viajeros podrán llevar consigo hasta $30 \mathrm{Kgs}$. de equipaje, a los que hay que añadir el transporte específico en grande y pequeña velocidad, en especial el último que alcanzó cifras superiores a los 100 millones de Tm/Km. Sólo para la Compañía del Norte. Todo ello fue unido a una sensible reducción de los precios, con el consiguiente aumento de la movilidad de la población". Artola, M. "La burguesía revolucionaria", pp. 100-105.

20. AHP La Rioja/Protocolos/Pedro Moreno/Sign.5752/P-120, FF.421-422.

21. AHP La Rioja/Protocolos/Pedro Moreno/Sign.5762/P-1, FF.1-4. 
vecinos de Málaga, y su gerente, el comerciante Manuel Carrillo Luque, para que reclamen de la empresa del ferrocarril Tudela a Bilbao, el valor de 6.000 fardos de paños, importantes $4.767,75$ ptas., mas el $15 \%$ de perjuicios, y cuyos fardos fueron facturados en la ciudad de Calahorra en agosto de 1874 .

No es este el único caso de reclamaciones al ferrocarril por extravío, cobros indebidos o robo. En 1878 se disuelve ${ }^{22}$ la sociedad "Benito y Compañía" de Arnedillo y los tres socios se dividen los géneros y créditos existentes de acuerdo al capital aportado, pero quedarán 1.994 ptas. proindivisas, al ser procedentes de una reclamación que tienen pendiente al ferrocarril de Tudela a Bilbao, así como otras 175 ptas., que es el valor de dos piezas de paño enviadas al comerciante Francisco Martínez, de Santo Domingo, y que fueron robadas del ferrocarril.

Ahora bien, ¿cuál era el mercado o los mercados hacia donde se dirigían las mercancías transportadas en las recuas de mulas de nuestros arrieros, las galeras, diligencias o ferrocarril?. Para acercarnos al conocimiento de dichos mercados volvemos a utilizar aquellos inventarios post-mortem de los fabricantes, que en algunos apartados expresan la relación de deudores (nombre, procedencia y cuantía), a favor de la testamentaría, para de esa forma acercarnos al conocimiento de los lugares con los que se establecieron relaciones comerciales. Además, hay otros protocolos donde se expresan los apoderamientos de personas para el cobro de deudas, generalmente de sociedades mercantiles.

De este modo hemos confeccionado un listado de cuentas de crédito de personas o sociedades comerciales, por años y lugar de origen de los acreedores riojanos, con el fin de conocer la red comercial que desarrollaron los industriales pañeros, así como los del lino y cáñamo; estos últimos, residentes en las localidades de Aguilar y Cervera del río Alhama.

Sobre la importancia de esta fuente nada vamos a añadir a lo dicho por otros. Los inventarios son documentos notariales realizados después de la muerte del sujeto. Estos constan de dos partes, el cuerpo de bienes (dinero en efectivo, muebles, ropas y otros enseres, materia prima, maquinaria y utillaje, géneros, fincas urbanas y fincas rústicas, inversiones y créditos a favor de la testamentaría), y el cuerpo de bajas, donde se expresan las deudas o créditos en contra de la testamentaría, las aportaciones del cónyuge sobreviviente (cuando lo había), donaciones y gastos del funeral.

Nosotros hemos decidido seguir los pasos dados por Parejo Barranco ${ }^{23}$ en su estudio sobre el textil antequerano, el cual basa el análisis del mercado textil de dicha localidad en las cuentas de crédito (o créditos a favor de la testamentaría), escrituradas en los inventarios, con el fin de establecer el área geográfi-

22. AHP La Rioja/Protocolos/Servando Ruiz/Sign.5726/P-71, FF.169-172.

23. Parejo Barranco, A., "La industria dispersa e industrialización en Andalucía: el textil antequerano (1750-1900)", Málaga 1987, pag. 315. 
ca de dicho mercado y analizar su evolución, bien sea mostrando su contracción o desarrollo.

En el caso de los otorgamientos de poder, hemos especificado el dinero que corresponde por deudas o créditos, porque lo buscado con este listado es proporcionar una visión amplia de las personas, sociedades y lugares con los que por un motivo o por otro los fabricantes cameranos entraron en contacto y mantuvieron relaciones; y sobre todo, para discernir aquellos créditos debidos a empréstitos o préstamos hipotecarios, de los estrictamente comerciales, donde el motivo del crédito o de la deuda, es debido a la venta de géneros.

El periodo que hemos abarcado con el análisis de las cuentas de crédito, se extiende desde 1866 hasta 1896, tiempo más que razonable para reconocer los mercados de la industria textil riojana. Hemos depurado los inventarios consultados en el sentido de no tomar en cuenta aquellos que sólo reflejan las deudas por préstamos hipotecarios o usurarios, en vez de las deudas comerciales que son las que ahora nos interesan. Asimismo hemos rechazado los inventarios de familiares pertenecientes a una misma industria (siempre que hubiera proximidad en las fechas), para evitar duplicidad en la toma en consideración de los mercados comerciales.

Atendiendo estas consideraciones hemos efectuado la lectura de veinticinco inventarios, en donde hemos localizado un total de 668 cuentas de crédito distintas.

Por otra parte, hemos recogido un total de cuarenta y siete apoderamientos (otorgamiento de poder) de 1861 a 1895, para el cobro de deudas contraídas por sociedades comerciales, tras el envío de diferentes géneros desde las localidades fabriles de La Rioja.

Bien, pues sobre este cúmulo informativo, podemos extraer algunas conclusiones en orden a determinar los mercados tradicionales del textil riojano en la segunda mitad del siglo XIX. Comenzando por los inventarios post-mortem, estos representan a las cuatro zonas principales de producción textil, siendo cinco los pertenecientes al Oja, diez a Cameros, dos al Cidacos y ocho al Alhama. Si bien son pocos los del Cidacos, estos son sumamente expresivos del mercado comercial, al ser significativamente dos de los fabricantes de mayor relevancia económica a escala provincial. Por su parte, cuantos inventarios aparecen el Alhama, son descriptivos del mercado del lino y el cáñamo, es decir, el lienzo y la alpargata. Cameros está sobrerepresentado debido a la puntillosa descripción de los inventarios que aparecen tanto en Ortigosa, como en Torrecilla, Villoslada y Soto; pero sobre todo, porque su mercado comercial, en conjunto, bien puede representar al de la industria textil provincial. En cuanto al Oja, a pesar de que sólo tiene significación informativa el mercado de los años setenta, sabemos que para finales de siglo su decadencia le impedirá competir en igualdad de condiciones con los otros centros fabriles del Cidacos o Cameros. 
En primer lugar, hay que destacar que de las 668 cuentas de crédito, el $51 \%$ pertenecen al mercado regional, es decir a personas o sociedades de pueblos de La Rioja, y de cuyo conocimiento personal se pueden derivar tres conclusiones.

Una, es que buena parte de dichas cuentas de crédito pertenecen a individuos localizados en localidades fabriles o en sus aldeas, o en localidades próximas a dichos centros fabriles, por lo que habría que suponer que los créditos existentes se deben, bien al sistema de cesión o alquiler de instalaciones para determinadas fases del proceso industrial, y para la finalización de unos paños o géneros pertenecientes a la industria dispersa; o bien al sistema de comercialización mediante arriería y trajinantes, los cuales se llevan los géneros al fiado.

Otra conclusión que se deriva del conocimiento de dichos individuos o sociedades, es que algunas cuentas pertenecen a fabricantes establecidos en localidades fabriles, parientes de los acreedores, de los cuales recaban la ayuda y el apoyo económico (aunque estos residan en otras localidades), ayuda que se plasma en la comercialización común de los géneros, el préstamo dinerario y el uso societario de las instalaciones.

Finalmente, la mayor parte de las localidades que no son o no están próximas a centros fabriles, pertenecen claramente a los llamados mercados regionales, donde las cabezas de partido judicial y la capital de la provincia, marcan la referencia del resto de los pueblos que se enmarcan en este amplio colectivo de localidades, que sumariamente se encuentran situadas en el valle del Ebro, desde Haro en la Rioja alta, hasta Alfaro en la Rioja baja.

Dinero cuentas de crédito según tipo mercado

\begin{tabular}{|l|l|l|r|r|r|r|r|}
\hline LUGAR & AÑO & \multicolumn{1}{|c|}{ FABRICANTE } & $\begin{array}{c}\text { MER, } \\
\text { NACIONAL }\end{array}$ & $\%$ & $\begin{array}{c}\text { MER. } \\
\text { REGIONAL }\end{array}$ & $\begin{array}{r}\text { TOTAL } \\
\text { PTAS. }\end{array}$ \\
\hline Ortigosa & 1866 & de la Riva, Gabriel & 88.985 & 78 & 24.499 & 22 & 113.484 \\
\hline Soto & 1866 & Fernández Domínguez, P. & 8.346 & 87 & 1.260 & 13 & 9.606 \\
\hline Aguilar & 1870 & Ruiz Jiménez, N. & 5.587 & 33 & 11.421 & 67 & 17.008 \\
\hline Ezcaray & 1870 & López Larrea. C. & 356 & 9 & 3.650 & 91 & 4.006 \\
\hline Ezcaray & 1870 & Ormazábal Villanueva, J. & 7.322 & 79 & 1.929 & 21 & 9.251 \\
\hline Aguilar & 1871 & Sáinz Guerrero, P. & 44.343 & 68 & 20.440 & 32 & 64.783 \\
\hline Ezcaray & 1871 & Lope Esteban, L. & 8.901 & 92 & 734 & 8 & 9.635 \\
\hline Ezcaray & 1872 & Herrán Pérez, E. & 96.946 & 65 & 52.855 & 35 & 149.801 \\
\hline Cervera & 1872 & Zapatero Pascual, M. & 1.398 & 16 & 7.592 & 84 & 8.990 \\
\hline Cervera & 1873 & Lafuente García, A. & 15.357 & 54 & 12.870 & 46 & 28.227 \\
\hline Cervera & 1874 & Moreno Ruiz, P. & 31.000 & 86 & 5.250 & 14 & 36.250 \\
\hline Enciso & 1878 & Alonso Gutierrez, T. & 230.686 & 64 & 130.377 & 36 & 361.063 \\
\hline Torrecilla & 1878 & Sáenz López Adalid, J. & 18.900 & 100 & & & 18.900 \\
\hline Cervera & 1881 & Miguel León, A. & & & 4.125 & 100 & 4.125 \\
\hline Enciso & 1881 & Tutor, H. & 31.302 & 66 & 15.767 & 33 & 47.069 \\
\hline Torrecilla & 1883 & García Artabeytia, L. & 8.743 & 64 & 4.952 & 36 & 13.695 \\
\hline
\end{tabular}




\begin{tabular}{|l|l|l|r|r|r|r|r|}
\hline LUGAR & AÑO & \multicolumn{1}{|c|}{ FABRICANTE } & $\begin{array}{c}\text { MER. } \\
\text { NACIONAL }\end{array}$ & $\%$ & $\begin{array}{c}\text { MER. } \\
\text { REGIONAL }\end{array}$ & $\begin{array}{r}\text { TOTAL } \\
\text { PTAS. }\end{array}$ \\
\hline Cervera & 1890 & Marín Madurga, J. & 15.362 & 87 & 2.196 & 13 & 17.558 \\
\hline Rasillo & 1890 & de la Riva Pérez, I. & 4.016 & 55 & 3.250 & 45 & 7.266 \\
\hline Valgañón & 1890 & Apestegui Blas, N. & 1.728 & 100 & & & 1.728 \\
\hline Ortigosa & 1892 & de la Riva Navarrete, A. & 11.778 & 39 & 18.449 & 61 & 30.227 \\
\hline Villoslada & 1892 & Martínez de Pinillos, T. & 62.689 & 100 & & & 62.689 \\
\hline Torrecilla & 1893 & Velilla Romero, T. & 4.339 & 37 & 7.386 & 63 & 11.725 \\
\hline Ortigosa & 1894 & de la Riva Navarrete, I. & 25.003 & 64 & 7.822 & 36 & 32.825 \\
\hline Torrecilla & 1894 & de la Riva Navarrete, E. & 4.344 & 77 & 1.291 & 23 & 5.635 \\
\hline TOTAL & & & 727.431 & 68 & 338.115 & 32 & 1.065 .546 \\
\hline
\end{tabular}

Fuente: Protocolos Notariales (Testamentarías) y Elaboración Propia.

Si ahora atendemos a las cuentas de crédito extra provinciales y antes de delimitar el mercado comercial que las sostiene, vamos a precisar, que del millón largo de pesetas adeudadas por las 668 cuentas escrituradas de 1866 a 1894 en veinticuatro inventarios, el $68 \%$ de esa cantidad ( 727.436 ptas.), pertenece a las cuentas de crédito comerciales de las diferentes provincias españolas, mas alguna francesa.

Pero vayamos por partes. En primer lugar vamos a diferenciar el mercado pañero o lanero, del de lino y cáñamo. Este último nos ofrece las siguientes consideraciones, según el cuadro resultante.

Cuentas de crédito: Industria Linera y Cañamera

\begin{tabular}{|l|l|l|}
\hline \multicolumn{1}{|c|}{$1 \mathbf{1 8 6 6 - 1 8 7 0}$} & \multicolumn{1}{c|}{$\mathbf{1 8 8 1 - 1 8 8 0}$} & \multicolumn{1}{c|}{ París } \\
\hline Aldea el Pozo (Soria) & La Mota (Lugo) & Bilbao \\
\hline Castilruiz (Soria) & Espadañedo (Zamora) & San Sebastián \\
\hline San Felices (Soria) & Carbajales (Zamora) & Barcelona \\
\hline Ayllón (Soria) & Mombuey (Zamora) & Pamplona \\
\hline Trébago (Soria) & San Tirso (León) & Tudela (Navarra) \\
\hline Villar del Campo (Soria) & Sepúlveda (Salamanca) & Estella (Navarra) \\
\hline Cigudosa (Soria) & Segovia & Barasoain (Navarra) \\
\hline Débanos (Soria) & Valladolid & Castejón (Navarra) \\
\hline Sotillo (Soria) & Cigudosa (Soria) & Fitero (Navarra) \\
\hline Valdemadera (Rioja) & Cascante (Navarra) & Zaragoza \\
\hline Aguilar (Rioja) & Torrellas (Zaragoza) & San Pedro Manrique (Soria) \\
\hline Inestrillas (Rioja) & Zaragoza & Gómara (Soria) \\
\hline Cervera (Rioja) & Madrid & Miranda (Burgos) \\
\hline & Plasencia (Cáceres) & Madrid \\
\hline
\end{tabular}




\begin{tabular}{|l|l|l|}
\hline \multicolumn{1}{|c|}{$\mathbf{1 8 6 6 - 1 8 7 0}$} & \multicolumn{1}{|c|}{$\mathbf{1 8 7 1 - 1 8 8 0}$} & \multicolumn{1}{c|}{$1881-1890$} \\
\hline & Cervera & Haro \\
\hline & Aguilar & Ezcaray \\
\hline & & Ventosa \\
\hline & & Logroño \\
\hline & & Calahorra \\
\hline & & Cervera \\
\hline & & Valverde \\
\hline & & Grávalos \\
\hline & & Valdemadera \\
\hline
\end{tabular}

Fuente: Inventarios Post-mortem y Elaboración Propia

La industria cañamera de la alpargata, muestra en los primeros cinco años escriturados 1866-1870 (merced a los datos que obran en las cuentas crédito), un mercado básicamente regional ${ }^{24}$, tanto por su entorno riojano como por el soriano.

En el periodo siguiente (1871-1880), la información ampliada permite ver el alcance, tanto de los tejidos de lienzo como de las alpargatas, situando el mercado en Galicia (Lugo), Castilla (León, Zamora, Salamanca y Soria), Extremadura (Cáceres), Navarra, Zaragoza y Madrid.

Finalmente, el periodo de 1881-1890 señala una apertura del mercado alpargatero que llega a París, Bilbao, San Sebastián, Barcelona, Zaragoza y Madrid, pero que se difunde mayoritariamente por los pueblos navarros, principalmente las ciudades de Estella y Pamplona, así como en lugares con estación de ferrocarril como Castejón, Calahorra, Logroño, Haro y Miranda de Ebro.

No es este el único mercado al que acceden los géneros de Cervera y Aguilar, ya que los lienzos ${ }^{25}$ y lonas tuvieron también por clientes habituales a los

24. "Estos alpargateros (Arnedo, s.XIX), vendían, colocaban, su producción en los pueblos de la provincia, que cada uno llevaba a domicilio a sus clientes y que lo mismo ocurría con los zapateros". León Gentico, J., "El fenómeno industrial de Arnedo y su incidencia en la comar$c a^{\prime \prime}$, Logroño 1979, pag. 45.

25. "El lino y el cáñamo los cosechan, enrían y agraman los mismos labradores, y sin más preparación pasan al mercado, de donde los toman los sogueros y alpargateros que por regla general son los que se dedican a espadarlos y rastrillarlos, para su inmediato uso o para expenderlos a su vez y proveer al pedido que ocasiona el hilado casero o doméstico. Una parte de los lienzos ordinarios y aun de clase más fina, que se consumen en muchos pueblos de la provincia, se hace por industriales que poseen un telar común. Es frecuente que el consumidor suministre el hilo recibiendo la tela producida, mediante una cuota en metálico o en especie de la misma primera materia. Además, los tejedores por su parte dan al comercio los géneros que elaboran con esas primeras materias o con las que directamente se procuran. En las indicadas condiciones hay establecidos sesenta y cuatro telares. La confección de alpargatas es otro de los ramos en que se consume la cosecha de materias textiles de la provincia y aun una por- 
Gobiernos de la Nación, la marina y los conventos, pero las noticias que nos proporcionan los inventarios de esta época, son sobre todo las referidas al mercado de la alpargata.

Cuentas crédito: Industria Pañera

\begin{tabular}{|c|c|c|c|c|}
\hline $1866-1870$ & $\begin{array}{c}\text { 1872: Pablo } \\
\text { Alemán }\end{array}$ & 1871-1880 & $1881-1890$ & $1891-1896$ \\
\hline $\begin{array}{l}\text { Santiago } \\
\text { (A Coruña) }\end{array}$ & Francia & Castroverde (Lugo) & Vigo (Pontevedra) & A Coruña \\
\hline $\begin{array}{l}\text { Betanzos } \\
\text { (A Coruña) }\end{array}$ & $\begin{array}{l}\text { Santiago } \\
\text { (A Coruña) }\end{array}$ & $\begin{array}{l}\text { Santiago } \\
\text { (A Coruña) }\end{array}$ & $\begin{array}{l}\text { Reinosa } \\
\text { (Santander) }\end{array}$ & $\begin{array}{l}\text { Santiago } \\
\text { (A Coruña) }\end{array}$ \\
\hline Padrón (A Coruña) & Molina (Oviedo) & Pontevedra & $\begin{array}{l}\text { La Peña } \\
\text { (Salamanca) }\end{array}$ & Noya (A Coruña) \\
\hline A Coruña & Pamplona & Oviedo & $\begin{array}{l}\text { Ledesmas } \\
\text { (Salamanca) }\end{array}$ & Vigo (Pontevedra) \\
\hline Orense & Irún & Burgos & Tabladillo (León) & Orense \\
\hline Pontevedra & Tolosa (Guipúzcoa) & $\begin{array}{l}\text { Vallejimeno } \\
\text { (Burgos) }\end{array}$ & Gómara (Soria) & Lugo \\
\hline Lugo & $\begin{array}{l}\text { Tarazona } \\
\text { (Zaragoza) }\end{array}$ & $\begin{array}{l}\text { Huerta Arriba } \\
\text { (Burgos) }\end{array}$ & Tajahuerce (Soria) & Lamela (Lugo) \\
\hline Ribadeo (Lugo) & $\begin{array}{l}\text { Mora Rubielos } \\
\text { (Teruel) }\end{array}$ & Tolbaños (Burgos) & Zarabes (Soria) & Oviedo \\
\hline Palencia & $\begin{array}{l}\text { Pon Armentera } \\
\text { (Lérida) }\end{array}$ & Aranda (Burgos) & Miñana (Soria) & Torrelavega \\
\hline Castrillo (Palencia) & Sabadell & Sahagún (León) & Quiñonería (Soria) & Toro (Zamora) \\
\hline $\begin{array}{l}\text { Mayorga } \\
\text { (Valladolid) }\end{array}$ & Barcelona & Palencia & $\begin{array}{l}\text { Fuentelmonje } \\
\text { (Soria) }\end{array}$ & Valladolid \\
\hline Soria & Valladolid & Astudillo (Palencia) & $\begin{array}{l}\text { Velilla los Ajos } \\
\text { (Soria) }\end{array}$ & Palencia \\
\hline Montenegro (Soria) & Belorado (Burgos) & Zamora & $\begin{array}{l}\text { Monteagudo } \\
\text { (Navarra) }\end{array}$ & León \\
\hline Béjar (Salamanca) & $\begin{array}{l}\text { Pradoluengo } \\
\text { (Burgos) }\end{array}$ & Peroniel (Soria) & La Vega (Cáceres) & Montenegro (Soria) \\
\hline Zaragoza & $\begin{array}{l}\text { Miguelañez } \\
\text { (Segovia) }\end{array}$ & Trébago (Soria) & Jaén & Villalba (Soria) \\
\hline
\end{tabular}

ción de los importados. Pero las industrias linera y cañamera en gran escala, están representadas por las fábricas de Aguilar y Cervera del Río Alhama, en el primero de cuyos pueblos, hay una de hilados y tejidos de lino, y en el segundo, dos de géneros de cáñamo. Estos establecimientos importan en su mayor parte las hilazas del extranjero especialmente de los mercados de Inglaterra y producen, la primera, mantelerías y lienzos de diferentes clases y las otras dos, telas para sacos y lonas dignas de mencionarse por su perfección". Delgado y Masnata, A.T., "Memoria sobre el estado de la agricultura e industrias derivadas en la provincia de Logroño", Logroño 1876, pp. 47 y 48. 
REDES DE TRANSPORTE Y COMERCIALIZACIÓN DE LA INDUSTRIA PAÑERA RIOJANA

\begin{tabular}{|c|c|c|c|c|}
\hline $1866-1870$ & $\begin{array}{c}\text { 1872: Pablo } \\
\text { Alemán }\end{array}$ & $1871-1880$ & $1881-1890$ & $1891-1896$ \\
\hline Ubeda (Jaén) & Astudillo (Palencia) & Oncala (Soria) & $\begin{array}{l}\text { Torre del Campo } \\
\text { (Jaén) }\end{array}$ & Madrid \\
\hline \multirow[t]{21}{*}{ Sevilla } & Béjar (Salamanca) & La Cuesta (Soria) & Alameda (Málaga) & Barcelona \\
\hline & Sonseca (Toledo) & Borobia (Soria) & Serón (Almería) & $\begin{array}{l}\text { Villanueva } \\
\text { (Badajoz) }\end{array}$ \\
\hline & $\begin{array}{l}\text { San Pedro } \\
\text { Manrique }\end{array}$ & Aldehuela (Soria) & & Guadix (Granada) \\
\hline & Sta.Cruz Yanguas & Yanguas (Soria) & & Sevilla \\
\hline & Madrid & Agreda (Soria) & & Jaén \\
\hline & Hervás (Cáceres) & Santa Cruz (Soria) & & \\
\hline & $\begin{array}{l}\text { Cabeza Buey } \\
\text { (Badajoz) }\end{array}$ & Valdeprado (Soria) & & \\
\hline & Córdoba & Olvega (Soria) & & \\
\hline & $\begin{array}{l}\text { Antequera } \\
\text { (Málaga) }\end{array}$ & Valladolid & & \\
\hline & Alcoy (Alicante) & Cubillo (Segovia) & & \\
\hline & & Guadalajara & & \\
\hline & & $\begin{array}{l}\text { Brihuega } \\
\text { (Guadalajara }\end{array}$ & & \\
\hline & & Alcalá (Madrid) & & \\
\hline & & Madrid & & \\
\hline & & $\begin{array}{l}\text { Tarazona } \\
\text { (Zaragoza) }\end{array}$ & & \\
\hline & & Estella (Navarra) & & \\
\hline & & Laguardia (Vitoria) & & \\
\hline & & Valencia & & \\
\hline & & Orihuela (Alicante) & & \\
\hline & & Almenara (Jaén) & & \\
\hline & & Granada & & \\
\hline
\end{tabular}

Fuente: Inventarios post-mortem y Elaboración Propia

Veamos ahora cómo se extiende el mercado de la fabricación pañera lanera de La Rioja, que tiene en los primeros cinco años (1866-1870), en que hemos recogido la información que nos proporcionan los inventarios post-mortem, su salida comercial en las cuatro capitales gallegas de La Coruña, Lugo, Orense y Pontevedra, así como en las localidades de Santiago, Betanzos, Padrón (La Coruña), y Ribadeo (Lugo).

También en plazas castellanas de Palencia y Soria, así como en las localidades de Castrillo de Villavega (Palencia), Mayorga (Valladolid) y Montene- 
gro (Soria). Hacia el este Zaragoza, y ya al sur Béjar (Salamanca), Ubeda (Jaén) y Sevilla.

Para apreciar la singularidad de las relaciones comerciales de los industriales de este periodo, hemos escogido unos inventarios que nos servirán de modelo sobre el flujo comercial que mantuvieron.

En 1866 tenemos dos inventarios, con los créditos o deudas a favor de la correspondiente testamentaría. La primera es la de un pequeño fabricante de Soto de Cameros, Pablo Fernández Domínguez, el cual diversifica sus actividades entre la elaboración de chocolate, tejido de paños y tienda de artículos varios. Este pequeño fabricante es acreedor de una serie de deudas por un monto total de 9.607 ptas., de las cuales, el $57 \%$ pertenece a una sociedad de Zaragoza, el $30 \%$ pertenece a individuos gallegos (Santiago y Betanzos), mientras que el $13 \%$ restante pertenece a individuos de su propia localidad.

La otra testamentaría es la de un gran fabricante de Ortigosa de Cameros, Gabriel de la Riva Moreno, de cuya sociedad podemos realizar un seguimiento hasta fines de siglo, a través de las testamentarías de sus deudos y familiares más directos. Sin embargo, debido al carácter mercantil de sus actividades, junto a las puramente fabriles, resulta la testamentaría de 1866 la más interesante de cuantas hemos encontrado. Gabriel de la Riva y su hermano Angel no sólo son los fundadores de una sociedad fabril que se prolongará hasta mediados de nuestro siglo ${ }^{26}$, sino que además son grandes comerciantes.

Del análisis de las deudas a su favor, podemos deducir cuáles fueron sus mercados principales; así, de un monto total de créditos a su favor por valor de $136.607,50$ ptas., el 44\% son de procedencia gallega (Pontevedra, La Coruña y Lugo, por ese orden descendente). Ahora bien, mientras la mayor partida es la de la sociedad "Señores Vázquez e Ibáñez Lande", de Pontevedra con 33.640 ptas., el resto esta sumamente repartido, sobre todo en Santiago de Compostela, donde destacan Mariana García (2.372,50 ptas.); la sociedad "Riva y García", la casa matriz de la futura cadena Simeón (10.665 ptas.); su nieto Enrique de la Riva, que por entonces trabaja en la casa comercial de Simeón como harán muchos de los hijos de Ortigosa (1.887,50 ptas.); Pedro Moreno Roldán (2.470 ptas.); Bruno Bartolomé, también acreedor del pequeño fabricante de Soto (4.437,50 ptas); y en Rivadeo (Lugo), Sebastián Escuder con 2.702,50 ptas.

Con el $23 \%$ de las deudas se encuentra Andalucía, y aunque esto se debe a la deuda contraída por su hijo político Pío de la Riva Aranceta, vecino de Ube-

26. "La comercialización de los paños se encontraba especializada hacia las aldeanas de Galicia. Lo mismo ocurría con las estameñas que eran más bastas y de tipo menos fino. Unas hermanas de la Riva se acercaban a Ezcaray para comprar de mejor calidad. También se especializó el mercado pañero de Ortigosa en el área de Barcelona, pero quien conservó su mercado por más espacio de tiempo fueron los Quemada (de Enciso), que llegaron a copar casi todos los conventos". Conversaciones con Carmen Rubio de la Riva, Ortigosa 1982. 
da (Jaen), con 27.000 ptas.; también es verdad que el resto son deudores de Sevilla, donde destaca por su cuantía "González y Maqueda", con 3.300 ptas.

Seguiría en orden descendente las deudas contraídas por vecinos de la provincia de Logroño con el $17 \%$, aunque hay que diferenciar por zonas, ya que en la inmediata al pueblo de Ortigosa se concentra el mayor número de deudores, con más de la mitad en el mismo Ortigosa, donde destaca por su cuantía la sociedad fabril "Riva y Riva" con un importe de 4.015 ptas., y que está compuesta por el hijo primogénito de Gabriel, Jose Matías de la Riva, y el entonces primo de éste último, Leoncio de la Riva, lo que remarca que los préstamos más importantes los efectuaba con los miembros familiares, individuos en los que la confianza para esta clase de negocios se supone. Precisamente las otras deudas de mayor cuantía son de miembros familiares, que asimismo se mueven en los negocios de la fabricación, por lo que es de entender que Gabriel, el patriarca de los negocios mercantiles, haría las veces de intermediario en la colocación no sólo de sus productos, sino también de los productos de los fabricantes de su entorno familiar, a los que adelantaría el valor de sus paños y bayetas. Así, aparecen su propio hijo Jose Matías (1.357,50 ptas.); y sus hijos políticos Gregorio Rubio (1.742,50 ptas.), y Nicomedes Navarrete (1.445 ptas.).

Otro lugar a destacar en el entorno geográfico de Ortigosa, es Gallinero de Cameros, donde aparecen cuatro deudores, donde destacan por su cuantía los ganaderos Tomás González (3.455 ptas.) y Francisco A. López (1.862,50 ptas.).

También en la provincia de Logroño, hay una serie de pequeñas deudas entre 62,5 y 125 ptas., que curiosamente proceden de personas situadas en pueblos fabriles como Munilla, Soto y Torrecilla, que bien pueden deberse a pagos adelantados por determinados productos de hilado, tejido o tintado, aunque no llegan a especificarse como en el caso de Montenegro y Viniegra de Arriba, donde se dice claramente que pertenece a las hilanderas, a cuenta de hilar. Por último, y sin salirnos de la provincia de Logroño, están las deudas contraídas por personas de Nájera y su entorno (Badarán, Huércanos y Villarejo), que nos inclina a entender, que Gabriel de la Riva, como buen comerciante, no dejaría pasar de largo el mercado de Nájera, ya que por entonces era uno de los más concurridos.

Ya en cuarto y quinto lugar con el $10 \%$ y el $5 \%$ están las deudas de pueblos que no hemos logrado situar y las de Castilla, donde aparecen dos deudores, uno de Soria con 5.337,50 ptas. (Miguel Lucía Moreno), que por su apellido podría tener algún parentesco con Gabriel; y otro de Béjar, Vicente Bueno, con 1.500 ptas. Precisamente en Béjar se encuentra un ortigosano, Paulino Navarrete Rubio, que trabaja en "Hijo de Arenzana y Compañía", junto a otros personas de origen ortigosano, lo que nos da a entender que para entonces hay un núcleo de cameranos avecindados, no sólo en Cáceres, Ciudad Real y Badajoz gracias a las actividades de la trashumancia (comerciantes y propietarios), sino en núcleos fabriles como Béjar (comercio y fabricación). 
Resumiendo lo antedicho, dos zonas son las de mayor calado comercial, las del entorno de La Coruña, merced al establecimiento de la casa comercial de Simeón García de la Riva en Santiago de Compostela, y las castellanas de camino hacia Galicia.

En la década de 1871 a 1880 el mercado es más amplio, añadiendo a las capitales de provincia anteriores, las de Oviedo, Zamora, Palencia, Burgos, Valladolid, Madrid, Guadalajara, Granada y Valencia, así como numerosas localidades del entorno gallego, castellano, aragonés y navarro como Castroverde (Lugo), Vallejimeno, Huera Arriba, Tolbaños y Aranda (Burgos), Sahagún (León), AstudiIlo (Palencia), Peroniel, Trébago, Oncala, La Cuesta, Borobia, Aldehuela, Almajano, Yanguas, Agreda, Santa Cruz, Valdeprado y Olvega (Soria), Cubillo (Segovia), Brihuega (Guadalajara), Alcalá (Madrid), Laguardia (Vitoria), Tarazona (Zaragoza), Estella (Navarra), Orihuela (Alicante) y Almenara (Jaén).

Mención especial hay que hacer del mercado del fabricante de cardas de Ezcaray, Pablo Alemán, que en el inventario de su mujer en 1872, muestra todos los puntos donde tiene su mercado en el que necesariamente concurren algunos de los principales centros fabriles españoles de la época, incluso Francia, hasta donde llega la venta de maquinaria industrial, como son Santiago (Coruña), Molina (Oviedo), Pamplona, Irún y Tolosa (Guipúzcoa), Tarazona (Zaragoza), Mora de Rubielos (Teruel), Pon de Armentera (Lérida), Sabadell (Barcelona), Barcelona, Valladolid, Belorado y Pradoluengo (Burgos), Migueláñez (Segovia), Astudillo (Palencia), Béjar (Salamanca), Sonseca (Toledo), San Pedro Manrique y Santa Cruz de Yanguas (Soria), Madrid, Hervás (Cáceres), Cabeza el Buey (Badajoz), Córdoba, Antequera (Málaga) y Alcoy (Alicante).

Ya en la década de 1881 a 1890, observamos cómo disminuye el volumen de cuentas de crédito, situándose estas tan sólo en las provincias de Pontevedra, Santander, Salamanca, León, Soria, Navarra, Cáceres, Jaén, Málaga y Almería, es decir en su mercado tradicional de Galicia, Castilla y Andalucía.

Finalmente, en los años de 1891 a 1896, el mercado más estable de los géneros riojanos, está formado por las provincias gallegas, sus capitales y localidades como La Coruña, Orense, Lugo, Santiago y Noya (La Coruña), Vigo (Pontevedra), Noya y Lamela (Lugo). Más al este Oviedo y Torrelavega (Santander). Hacia el sur, los pueblos de Soria, León, Palencia, Toro (Zamora), así como Valladolid, que son un camino trillado de los arrieros riojanos, manifestándose ésta última ciudad como centro de operaciones y almacén de algunos fabricantes del Cidacos, Cameros y el Alhama, sobretodo, en cuanto hace relación con el gran mercado madrileño y su entorno de Alcalá y Guadalajara. Barcelona, al este de la península, es una plaza que las estrategias comerciales de fabricantes del Oja, Cameros y Cidacos han situado entre las habituales pese a la proximidad de los centros laneros de Sabadell y Tarrasa, posiblemente a instancias de las redes familiares, que para entonces habían afianzado una de las sociedades comerciales de mayor calado nacional, la de los Riva y García. Al 
sur los mercados tradicionales de Sevilla y Jaén, se ven ampliados con los de las provincias de Granada y Almería. Por su parte, localidades del entorno extremeño, como Villanueva del Fresno (Badajoz), allá donde algún elemento de la amplia red de cameranos ha sentado sus reales, recoge las mercancías que sus paisanos le encomiendan en sus viajes arrieriles.

Dos ejemplos interpuestos de las localidades cameranas de Ortigosa y Torrecilla, mejorarán nuestra visión de este amplio mercado de carácter popular.

En 1894, cuando fallece la mujer de Nicomedes Navarrete, los socios de "Navarrete Hermanos", reconocen unas deudas a favor de la testamentaría de su madre de 25.000 ptas., de las cuales el 57\% proceden de Galicia, principalmente de La Coruña y sus poblaciones de Santiago (Simeón García) y Noya (hermanos Leiciaga), por este orden. Un $23 \%$ responde a la entonces Castilla la Vieja (Santander, León, Palencia y Valladolid), a donde llegan los todavía paños y bayetas. El 16\% de las deudas proceden de Oviedo, donde hay dos compañías mercantiles, futuro embrión de sucursales de la casa Simeón. Finalmente el 3\% son deudores de la provincia de Logroño, donde se distingue Viniegra de Arriba, merced a la deuda de Bonifacio García.

Un último inventario nos fijará el mapa comercial de las fábricas pañeras de Cameros, pues esta vez tomamos una de Torrecilla (1894), en concreto la fábrica de Pedro Sáenz Díez, la cual tiene relaciones comerciales con Galicia, casa "Simeón García" (Santiago) y "Simeón García y Cía" (Orense), y con Andalucía, a través de "Echeverría hermanos" (Granada), Gregorio Ruiz (Guadix) y "Sáenz, García y Herrero" (Jaen).

En la provincia también destaca la deuda de la entidad financiera "Herrero y Riva" (Logroño), señal de que tales señores son habituales apoderados del fabricante.

\section{Los apoderamientos para el cobro de deudas}

A fin de ahondar en el conocimiento de los mercados hacia el que se dirigen las mercancías producidas por los establecimientos fabriles de la provincia de Logroño en la segunda mitad del XIX, hemos recabado información sobre los otorgamientos de poder para el cobro de deudas, escriturados en diferentes protocolos notariales.

Merced al cuadro siguiente, se puede ampliar la información que ya habíamos reunido tras leer los inventarios post-mortem, de tal modo que para el periodo de 1861 a 1870 tan sólo podemos anotar la falta de deudas en las provincias gallegas, pero sí en las castellanas de Palencia y Zamora, o en las andaluzas de Granada, Málaga y Sevilla. La novedad procede de la deuda de Bilbao, primera y única vez de la que tenemos referencia. 
En el siguiente decenio (1871-1880), aparece como novedad Barcelona, y ya de modo tradicional, el mercado castellano, significado por Segovia, Palencia, Madrid, y las provincias andaluzas de Almería, Cádiz, Málaga y Córdoba.

El siguiente periodo (1881-1890), nos vuelve a señalar los entornos casteIlanos y andaluces, así como Zaragoza, Valencia y Cáceres.

El corto periodo de 1891 a 1895 insiste en dichos mercados castellanos y andaluces. Así pues, Galicia, Castilla (incluso Madrid y su entorno) y Andalucía, y en menor medida, Extremadura, Oviedo, Zaragoza; y en contadas ocasiones Valencia, Barcelona y Santander, son los mercados tradicionales de la industria pañera riojana en la segunda mitad del siglo XIX, tal y como deducimos del cuadro siguiente:

Apoderamientos para cobro de deudas

\begin{tabular}{|c|c|c|c|c|c|}
\hline AÑo & LUGAR & FABRICANTE & PTAS. & DEUDOR & LUGAR \\
\hline 1855 & Munilla & Fernández Torre, $M$. & 266 & Barceló, M. & Tarazona \\
\hline 1861 & Munilla & Enciso e Hijos & 870 & Ferrer y Lucavats & Granada \\
\hline 1861 & Munilla & Enciso e Hijos & 2.209 & Ruiz y Cía, J. & Málaga \\
\hline 1866 & Munilla & Enciso e Hijos & 2.184 & del Valls, J. & Granada \\
\hline 1866 & Munilla & Enciso e Hijos & & & Sevilla \\
\hline 1866 & Enciso & Alonso, $\mathrm{S}$. & 1.686 & Ortiz, F. & Osorno \\
\hline 1868 & Munilla & Enciso y Enciso, $M$. & 5.716 & de la Torre, $M$. & Bilbao \\
\hline 1868 & Enciso & Ruiz, J. & 1.800 & Junquera Pérez, F. & Zamora \\
\hline 1869 & Munilla & Fernández Hnos. & 2.280 & Díaz, M. & Granada \\
\hline 1869 & Ezcaray & Alemán, $\mathrm{P}$. & 525 & García, J. & Antequera \\
\hline 1871 & Ezcaray & Alemán, $P$. & 1.881 & Varios & Migueláñez \\
\hline 1871 & Munilla & Mendiola, $\mathrm{C}$. & & García Vinuesa, S. & Madrid \\
\hline 1871 & Enciso & Ruiz de Alonso y Riva & & García Vinuesa, $\mathrm{S}$. & Madrid \\
\hline 1872 & Enciso & Ruiz, J. & 1.500 & Ortiz, F. & Osorno \\
\hline 1872 & Enciso & Gutiérrez e Hijos & 452 & Bianchi Hnos. & Barcelona \\
\hline 1874 & Enciso & Gutiérrez e Hijos & 831 & Fernández y Mtnez, V. & Enciso \\
\hline 1875 & Munilla & Fernández Hnos. & & Ramón y López, F. & Cádiz \\
\hline 1876 & Enciso & Gutiérrez e Hijos & 1.397 & Giménez Fuentes, J. & Almería \\
\hline 1879 & Enciso & Gutiérrez e Hijos & & & Priego \\
\hline 1879 & Enciso & Gutiérrez e Hijos & & & Málaga \\
\hline 1879 & Munilla & Pío Aguirre y Hno. & 706 & Guillên, J. & Almería \\
\hline 1879 & Munilla & Pío Aguirre y Hno. & 1.288 & Savater Guardiola, A. & Priego \\
\hline 1879 & Munilla & A.Torre e Hijos & & Tranchez, A. & Vigo \\
\hline 1882 & Enciso & Córdova, A. & & & Málaga \\
\hline 1885 & Munilla & Esteban Enciso e Hijos & 1.733 & del Prat, $M^{a}$ Angel & Valladolid \\
\hline 1886 & Munilla & Hijos de Norberto Solana & 250 & Monllor Abad, R. & Granada \\
\hline 1887 & Enciso & de la Riva, C. & 3.297 & Azcárate, P. & Alcalá Henar. \\
\hline 1887 & Enciso & Enciso y Enciso, $\mathrm{M}$. & 2.459 & Cascales Ruiz, P. & Granada \\
\hline
\end{tabular}




\begin{tabular}{|l|l|l|r|l|l|}
\hline 1887 & Enciso & Esteban Enciso e Hijos & 339 & Benítez, P. & Almería \\
\hline 1888 & Munilla & Fernández Hnos. & & Sebastián, A. & Granada \\
\hline 1888 & Enciso & Quemada Enciso, M. & & García San Millán, F. & Zamora \\
\hline 1888 & Ezcaray & Perujo, Félix & & Córdova, R. & Ezcaray \\
\hline 1888 & Ezcaray & La Industrial Castellana & & Bertolín Blasco, J. & Valencia \\
\hline 1889 & Ezcaray & Vda. De Lope e Hijos & & Bautista Lacoma, J. & Calahorra \\
\hline 1889 & Ezcaray & La Industrial Castellana & & Rubio, H. & Zaragoza \\
\hline 1889 & Ezcaray & González Rabayoye, J. & 303 & Perujo, F. & Ezcaray \\
\hline 1890 & Ezcaray & Vda.de C.Calvo e Hijos & 684 & González, F. & Plasencia \\
\hline 1890 & Aguilar & Mayor Ruiz, E. & & & Palencia \\
\hline 1890 & Enciso & Vda. e Hijo Gutiérrez, C. & & Herrero y Cía. & Ronda \\
\hline 1891 & Ezcaray & Vda. González Rabayoye & & La Legalidad SA & Ezcaray \\
\hline 1891 & Ezcaray & Vda. González Rabayoye & 2.000 & Galobardes Hnos. & Ezcaray \\
\hline 1891 & Ezcaray & Vda. González Rabayoye & 510 & Galobardes Hnos. & Ezcaray \\
\hline 1891 & Torrecilla & Sáenz Díez, P. & & Martínez Hnos. & Granada \\
\hline 1891 & Munilla & Enciso y Águirre, S & & & Andújar \\
\hline 1891 & Munilla & Sevilla, C. & 5.279 & Martínez Hnos. & Granada \\
\hline 1892 & Ortigosa & García, A. & 1.171 & García San Millán, F. & Toro \\
\hline 1895 & Ortigosa & Sáenz Pérez, I. & & Sáenz, Romero y Pérez & Almería \\
\hline
\end{tabular}

Fuente: Inventarios Post-mortem y Elaboración Propia

\section{Relaciones comerciales de fabricantes cameranos}

Finalmente, hemos reconocido en diferentes protocolos notariales, hasta ciento once sociedades comerciales relacionadas de un modo $\mathrm{u}$ otro con industriales cameranos (principalmente de Ortigosa y Torrecilla), desde 1866 hasta 1896; algunas de ellas, forzosamente repetidas en ciertas cuentas de crédito o en ciertos otorgamientos de poder para cobro de deudas; y donde se expresaba una relación, bien societaria, o bien comercial, generalmente a través de parientes interpuestos en dichas sociedades.

Veamos cuáles eran estas sociedades en el siguiente listado:

\section{Cameros, 1865:}

"Hijos de Martín Sanz" (Valladolid) Cameros, 1866 (diferentes protocolos):

Benito Bonel e Hijos (Tarazona)

Matías Pérez (Valladolid)

El heredero de Cenón Pérez (La Coruña)

Simón Guinea (Miranda de Ebro)

Cameros, 1867:

Juan Torre (Villanueva del Fresno)

Félix Giménez (Antequera)

Cameros, 1868:

Pedro Ardita (Mérida).

Iginio Pinillos Rubio (Málaga)
Cameros, 1869:

Pedro Sáenz Díez relacionándose comercialmente con (Granada)

Angel Romero (Soria)

Ramón Rubio (Madrid)

Anselmo Navarrete de Torres, en "Guillot, Sanguinetti y Talco" (Montevideo, Uruguay).

Cameros, 1870:

Marcelino de la Riva y García con la sociedad "Basilio del Camino y Hermanos" (Sevilla)

Florencio y Matías García Lozano (Puente Cesures -Pontevedra-).

Eusebio de la Riva y Navarrete (Santiago) 
Julián Rubio de la Riva (Padrón)

Isidoro de la Riva y Riva (Padrón).

Tiburcio Pérez de la Riva (Madrid).

Cameros, 1871:

Ramón de la Riva y Riva (Santiago)

Josefa Somos y Rivero (La Coruña).

Cameros, 1873:

Apolinar García Navarrete (Vigo).

Julián Sáenz García y Félix García y García

(Jaen).

Mateo Sáenz López e Ibarra (Orihuela).

Cameros, 1874:

Pío de la Riva Aranceta (Quesada -Jaen-).

José Ceballos Bustamante (Santander),

Cameros, 1875:

Luis Aparicio (Córdoba).

Cameros, 1876:

María Sorzano y Adalid (Orihuela)

Carlos Ibarra Sorzano (Buenos Aires)

Victoria García y García, Juana García y García

(fallecidas) y Julián Sáenz García y Domingo y

Félix García y García, en "Matías Sáenz y Cía" (Jaen)

Cameros, 1877:

"Pedro Giménez y Hermano" (Sevilla).

Cameros, 1878:

Isidoro de la Riva y Riva (fallecido) y Félix Martínez de la Riva (Padrón).

Petra, Faustino, Mateo y Felipe Sáenz López e Ibarra (Orihuela)

Tomás y Tiburcio Sáenz López y Román (Filipinas)

Manuel Pastor Arbuces (Orihuela).

Cameros, 1879:

Tiburcio Pérez de la Riva (Madrid)

Julián Rubio de la Riva (+ Padrón).

Cameros, 1880:

Lucas Navarrete Rubio (Badajoz)

Paulino Navarrete de la Riva (Oliveira-Badajoz-).

Julian Sáenz García (Jaen)

Félix García García (Jaen)

Alejandro y Victoriano Sáenz Pérez (Santiago)

Norberto de la Calle "Calle y García": "Calle y

Sáenz Hermanos".

Simeón García de la Riva en "Simeón García y

Cía" (Santiago).

Cameros, 1881:

Julián Rubio de la Riva y Tiburcio y jose Ramón Pérez de la Riva: "Sobrinos de Julián de la Riva" (Madrid).
Apolinar García Navarrete, Mauro Fernández Cabezo y Victoriano Martínez de la Escalera: "García y Martínez" (Vigo).

Cameros, 1882:

Juan Cabora (Valparaíso -Chile-).

Marcelino de la Riva García y Deogracias Moreno de la Riva (Sevilla).

Pío de la Riva Aranceta y Prudencio de la Riva

(Quesada -Jaen)

José Ruiz y García (Quesada -Jaen-).

Diego Moreno de la Riva (Madrid)

Julian Moreno de la Riva (Lugo)

Blas Navarrete de la Riva (Santiago)

Alejandro Navarrete de la Riva (Santiago)

Juan Tabora (Argentina).

Cameros, 1883:

Cayo Brieva y Cuadra (Sevilla)

"Canals Canavells y Cía" (Barcelona).

Señores García y Fernández (Vigo)

Anselmo Martínez (Reinosa),

Cameros, 1884:

María Angel del Prado (Villalón).

Cameros, 1885:

Lino Sáenz de la Riva (Pontevedra)

Rafael Sáenz Díez de la Riva (Castuera -Cáceres-).

\section{Cameros, 1886:}

"Dionisio Lascano y Cía" (Vigo)

Pablo, Félix, Agustín y Eusebio Navarrete Rubio (Ubeda)

Justo Navarrete Rubio (Villacarrillo)

Cameros, 1887:

Francisco Lozano y García (Almendralejo). Julián y Anselmo Sáenz García y Félix García y García (Jaen).

Pedro Navarrete de la Riva (La Estrada -Pontevedra-).

Cameros, 1889:

Lucas García Navarrete apodera quien le represente en (Fregenal de la Sierra -Badajoz-).

\section{Cameros, 1890:}

Cándido Fraile y Matute (Almodóvar del Campo).

Matías Sáenz y Compañía (Jaen)

Antonio Guzmán (Jaen)

Bartolomé Barra (Torre del Campo)

Damián Parras (Torre del Campo)

Antonio Armenta (Jaen)

Antonio Alcántara (Torre del Campo)

Manuel Giménez (Torre del Campo)

Herederos de José Moreno (Jaen)

Juan Jurado (Torre del Campo)

Cameros, 1891:

"Martínez Hermanos" (Granada). 
Alejandro Navarrete de la Riva (Noya)

Blas Navarrete de la Riva (Argentina)

Cameros, 1892:

Teófilo Sevilla y Villar (Pradoluengo).

Francisco Alonso (Villanueva del Fresno)

Juan Alfonso (Villanueva del Fresno)

Melchor Romero (Puente Genil)

Julián Lacalle y de la Hera (Santa Marta -Bada-

joz-).

Dámaso Santamaría (Santiago),

Viuda de Florencio García (Santiago)

Andrés García (Bilbao)

Sucesores de Matías Sáenz y Compañía (Jaen)

Cameros, 1893:

Juana Bautista García Valdés y Rafael Ortiz y

Rodríguez (Quesada -Jaen-)

Lucas de la Riva (Santiago)

Aniceto Fraile y Matute (Madrid)

Benito Guerrero y Gamero (Sevilla)

\section{Cameros, 1894:}

Angel Sáenz Díez de la Riva (Vigo)

Acisclo Sáenz Díez de la Riva (Santiago)

Segundo Lerdo de Tejada y Moreno (Madrid).

Miguel Calle y García "Camiade, Carterón y

Calle" (Bayona)

Eusebio Campo Rodríguez (León)

Cameros, 1895:

Rufino, Juan y Vicente Sáenz Pérez (Almería)

"Miguel Santiago y Cía" (Buenos Aires).

Eulogia y Vicente Martínez Rubio: "Pinillos, Izquierdo y Cía" (Sevilla).

Francisco Herreros y Pérez (Quesada -Jaen-)

Cameros, 1896:

Aniceto de la Riva y de la Riva (Sevilla)

Deogracias Moreno de la Riva

Leopoldo Sáenz Díez García (Orense)

Fausto Sáenz Díez y García (+ Santiago)

Con este listado de personas y sociedades relacionadas comercialmente con los fabricantes cameranos de los valles del Iregua y Leza, lo que pretendemos, es mostrar no sólo la impronta del tráfico comercial, sino el hecho más significativo, cual es, que muchas de estas sociedades están formadas por miembros del amplio grupo de parentesco de los fabricantes cameranos. Esto explicaría, en buena medida, la pervivencia de unos mercados más allá de las contingencias económicas o productivas; puesto que la red familiar, con su asentamiento en las diferentes capitales gallegas y andaluzas, principalmente, pero también de Madrid, Barcelona y América ${ }^{27}$ (Chile y Argentina), defenderá los intereses de los fabricantes cameranos como suyos; dada la tupida urdimbre familiar o de parentesco, económica y crediticia, que les une a todos, fabricantes y comerciantes.

Hemos nombrado Galicia como uno de los principales centros receptores de los paños cameranos, dada la amplia red familiar existente en sus provincias, procedente de unas relaciones comerciales entre los pueblos fabriles de Cameros y Galicia, que como una constante se manturieron desde el siglo XVIII merced a la arriería. Es más, cuando la penetración de los productos catalanes y extranjeros dentro del mercado nacional, de mejor calidad y desde mediados del XIX más competitivos, todavía los paños y bayetas de Ortigosa de Cameros, sostuvieron sus mercados gallegos tradicionales.

27. "Las fábricas de Soto de Camero Viejo, que tenían despacho en sus domicilios y sus géneros eran adquiridos, unos por los naturales para vestirse, y los más, para venderlos -como los llevaban los comerciantes y tratantes de esta villa y sus contornos-a la ribera, montañas de Burgos, Vizcaya, Galicia, Tierra de Campos, Madrid y los cuatro reynos de Andalucía, la Mancha, provincia de Extremadura y reino de Navarra, en algunas ocasiones también se fabricó para embarcar a indias". Ochagavía, D. "Historia textil riojana", pag. 96. 
Ya hemos comentado que los hermanos de Ortigosa, Gabriel y Angel de la Riva sostuvieron junto a la fabricación textil, el comercio en arriería con Pontevedra, especialmente con el Partido judicial de Caldas de Reyes ${ }^{28}$. En un pueblo de este partido judicial, en Ponte Cexures, se encuentra un primo carnal de Simeón García de la Riva, un año mayor que él, llamado Matías García Lozano ${ }^{29}$, que como Simeón:

"Salió de la casa paterna a los 14 años, con la debida autorización para Galicia, en donde tenía parientes con el objeto de dedicarse a la carrera mercantil. El Matías García Lozano, por la irreprensible conducta que siempre observó, e inteligencia adquirida en la profesión, mereció el aprecio general y, por ello, su señor tío Francisco Lozano González, vecino y del comercio que ha sido en dicho Puente Cesures, le invitó y se prestó a pasar a su casa y establecimiento para auxiliarle en él, y en los que tenía en otros puntos en los negocios mercantiles. Penetrado dicho señor de sus buenas prendas le concedió alguna participación de utilidades y, encontrándose célibe en edad avanzada, sin descendientes ni ascendientes, por el testamento que otorgó en 5 de junio de 1859 ante Jose María Batalla de San Miguel, notario del Distrito de la villa de Padrón, correspondiente al Colegio de la Audiencia Territorial de La Coruña, instituyó al Matías, y a su hermano Florencio García Lozano, vecino de la ciudad de Santiago, mayor de 25 años, casado, comerciante y a Tomás Lozano y Lozano, vecino de Puente Cesures, por sus herederos a partes iguales.

El Matías, desde que salió del país, no sólo de los chorros de sus honorarios, sino también de la parte de utilidades que le concedió su señor tío y más qụe lícitamente agenció, franqueó a su padre (Anselmo García Sánchez, residente en Ortigosa), muchas veces, varias partidas en metálico para sus atenciones.

Habiendo fallecido el Francisco Lozano González en noviembre de 1863, sin otra disposición que la anteriormente citada (...). Posteriormente, determinaron el Tomás Lozano y Lozano y el Matías García Lozano, formar sociedad bajo la razón de "Francisco Lozano y sobrinos", en Puente Cesures, la que efectivamente constituyeron y últimamente, ambos sujetos se asociaron con el señor Andrés de la Riva, de la villa de Padrón, para negocios comerciales con la denominación de "Riva, Molino y Lozano".

Así pues, el modo de ingresar en la carrera mercantil, es por apoyo de familiares que ya se encuentran establecidos en algún lugar del territorio español, prin-

28. Xoan Carmona señala que, a fines del XVIII, la comarça de Padrón es una excepción en el fenómeno de la industria dispersa gallega, al registrarse en ella tejedores a tiempo completo. $Y$ donde, paralelamente, una parte importante de las subsistencias (más de la mitad de los cereales en el conjunto de la jurisdicción) se traen «de las feligresías comarcanas, y aun en pan cocido de Santiago y Caldas", villas ambas situadas en un radio de unos $20 \mathrm{Km}$. Carmona Badía, X., "De fábrica dispersa a pariente de aldea. La cuestión industrial en los orígenes de la Galicia contemporánea", en Fernández de Pinedo y Hernández Marco (eds.), "La industrialización del norte de España", Barcelona 1988, pag. 90.

29. AHP La Rioja/Protocolos/Castells y Navarro/Sign.7347/23-2-1865. 
cipalmente Galicia para los ortigosanos, merced a la tradición manufacturera, arrieril y comercial de sus antepasados y paisanos, así como la emigración temporal gallega ${ }^{30}$, puente abierto al intercambio de toda clase de bienes y personas.

También nos hemos fijado en que las principales deudas que aparecen en los inventarios pertenecen a una casa comercial, la que fundara Simeón García de la Riva, del que cuentan, que en 1845, a los doce años de edad, se dirige a Santiago de Compostela y según el relato de un cronista $^{31}$,

"Tras largo y penoso viaje a lomos de molesta cabalgadura, donde hacía varios años se encontraba su hermano mayor, Timoteo, dedicado a la profesión mercantil. Comenzó sus trabajos comerciales en la casa de Dña.Cayetana Ramos, viuda de Nieto. (...). No tardaron en manifestarse las dotes y facultades extraordinarias que poseía, y cuando sólo contaba veintiún años, la muerte prematura de su hermano le obligó a ponerse al frente del negocio para ayudar y proteger los intereses de la viuda y dos hijos".

Siguiendo el relato de este cronista ${ }^{32}$ podemos avanzar los logros comerciales de este ortigosano, antes de introducir los elementos que nos interesan acerca de las estrategias matrimoniales y de reproducción social de los cameranos decimonónicos.

“En el año 1857 se asocia con su hermano político D.jorge de la Riva, (organizando lo que posteriormente se denominará Banco Simeón y que por entonces no era sino una casa de comisión); años después, en 1867, queda la Sociedad con el único nombre de "Simeón García"; en 1872 crea una nueva, denominada "Simeón García y Cía". Mas el reducido campo comercial de Compostela era pequeño para el desarrollo de sus actividades y talento, y su genio emprendedor le impulsa a mayores empresas, fundando en Barcelona, en el año 1877, la entidad comercial "Nieto, García y Riva", que años después se transformará en "Riva y García", una de las firmas comerciales más prestigiosas de España.

Al año siguiente se inauguran las casas de Villagarcía de Arosa, Orense y Coruña, todas con la razón social "Simeón García y Cía", mas otras en Alcoy, Vigo y Bilbao. (...). Mucho deben los ortigosanos a D.Simeón. Amante de su pueblo, eligió preferentemente a sus paisanos para trabajar a su lado, y varios de ellos deudores son a D.Simeón de la posición que hoy disfrutan".

Como se puede deducir del texto anterior, la existencia de miembros del linaje de la Riva en la constitución de las sociedades comerciales es un hecho ${ }^{33}$. 1960.

30. Meijide Pardo, A. "La emigración gallega intrapeninsular en el siglo XVIII", Madrid

31. Martínez Olmedo, L. "La villa de Ortigosa de Cameros", pag. 126.

32. Martínez Olmedo L. "La villa de Ortigosa de Cameros", pag. 127.

33. "Castro y Cía" se forma en 1885 al entrar Simeón García de la Riva y Jorge de la Riva en la antigua "Castro y Otero", pequeña sociedad que habían formado en 1877 dos comerciantes vigueses. Una vez asentados en el mercado vigués, los de la Riva se desharán de sus 
No sólo por la existencia de su hermano político Jorge de la Riva, ni por su matrimonio en 1866 con Juana Blanco Navarrete, sobrina de Gabriel y Angel de la Riva, sino por la constitución en Barcelona de "Nieto, García y Riva", más adelante denominada "Riva y García", casa comercial y casa de comisión que mantendrán los hermanos Vitoriano, Enrique y Benigno de la Riva, sobrinos y yerno respectivamente de Simeón.

Otros datos que nos confirman ese entramado de parentesco y negocios, son los préstamos crediticios que se manifiestan en los testamentos de nuestros protagonistas, como por ejemplo, el ya citado de Isidora de la Riva Navarrete, hija de Gabriel de la Riva y prima de Simeón, y heredera al enviudar de una fábrica textil (la de Nicomedes Navarrete), que en el momento de su fallecimiento en Barcelona, en 1893 (estancia debida a las relaciones existentes con la casa Riva y García de sus sobrinos Enrique, Victoriano y Benigno), tenía como mayor acreedor a Simeón García, de Santiago por un importe de 4.270,85 ptas. y a Sáenz y Compañía, también de Santiago, con 2.241,75 ptas., y en cuya organización empresarial está su yerno Acisclo Sáenz Díez.

Otro testamento abierto en la misma fecha, y del que también hemos hecho mención, es el de Eulogia de la Riva, hija de Angel de la Riva y prima de Simeón; también propietaria junto a su marido Pedro Sáenz Díez, de edificios fabriles en Torrecilla de Cameros, y en el cual están entre sus herederos, sus hijos Angel y Acisclo Sáenz Díez de la Riva, vecino de Vigo el primero y de Santiago el segundo, los dos dedicados al comercio. A ellos y a su marido lega entre otras cosas algunos créditos concedidos contra diferentes personas, siendo también los de más cuantía los otorgados a Simeón García, de Santiago (1.500 ptas.) y a Simeón García y Compañía, de Orense (1.000 ptas.). También contra la casa de banca logroñesa Herrero y Riva se encuentra un crédito de 641 ptas.

Así pues, la determinación de los negocios de préstamo y crédito entre los miembros del grupo familiar va a ser una constante en el desarrollo patrimonial de estas familias. Préstamos que dan lugar a las Ilamadas Casas de Comisión (como la de Herrero y Riva en Logroño, la de Riva y García en Barcelona y la de Simeón García en Santiago y otras ciudades), y créditos, fundados principalmente, en el suministro de telas y paños para lo que suponen el eje de los negocios mercantiles, que no son otros, que los de almacenes textiles al por mayor $^{34}$; aunque unos y otros, siempre enmarcados en una red, en una trama

socios indígenas, y se integrrá en "Viuda e hijos de Simeón García". Esta firma recibía los suministros de "Nieto, García y Riva" de Barcelona y de "Batí y Riva" de Alcoy. Carmona Badía, X. "El atraso industrial de Galicia", Barcelona 1990, pag. 227.

34. Los de la Riva, Orense, etc., formaban parte de clanes familiares dedicados al negocio textil extendidos por toda España. Isidoro de la Riva era además miembro, con un primo residente en Londres y con varios comerciantes sevillanos y madrileños, de una sociedad domiciliada en Madrid y dedicada a negocios de importación de hilados de lino escoceses. En la primera de ellas los socios son además Tiburcio Pérez de la Riva (residente en Londres), Angel y Esteban Mansilla (de Madrid y Londres), José Finat y Pascual Herranz, ambos de Madrid. En 
de relaciones, cuyo marco de desarrollo es el parentesco y su expresión mediata, los enlaces matrimoniales.

\section{Recapitulando}

Los productos y mercancías producidas por los fabricantes y artesanos riojanos, tuvieron dos mercados, el interior y el nacional. Para el mercado nacional, el medio de transporte más usual, hasta que el ferrocarril tomó carta de naturaleza (último cuarto del siglo XIX), fueron las recuas de mulas y galeras conducidas por arrieros y ambulantes. Si la arriería formaba parte de las actividades tradicionales y complementarias, de los pueblos fabriles de La Rioja; la venta en ambulancia estuvo más motivada por las necesidades económicas de aquellos campesinos desposeídos de tierras de labrantío.

En cualquier caso, el oficio de transportista a lomos de mulas o caballerías, estuvo en consonancia con el mal estado de las comunicaciones y la escasa infraestructura viaria. Los miembros de la burguesía industrial, interesados en la mejora de las comunicaciones con sus localidades fabriles, no fueron tampoco ajenos a las posibilidades de negocio que se les abrían con la construcción de carreteras y nuevos viales. No obstante, las posibilidades de movilización política, también fue un determinante para la construcción de nuevos viales, como se deduce del electorado votante, restringido a la clase burguesa, propietaria, comercial e industrial.

En el último cuarto de siglo, el ferrocarril modificará la perspectiva anterior, y hacia él se dirigirán los esfuerzos inversores de los hombres más pudientes de la burguesía provincial. Sin embargo, pese a estos intereses inversores, las líneas del ferrocarril quedarán alejadas de las localidades industriales del textil, principalmente de Ezcaray y las villas del Cidacos; y cuando se construyan, la decadencia de la industria pañera, inutilizará las esperanzas depositadas en la llegada del ferrocarril.

Los mercados interiores, reconocidos a través de las cuentas de crédito expresadas en inventarios post mortem, señalan que los destinatarios son individuos localizados en localidades fabriles, o en localidades próximas a dichos centros fabriles; por lo que es de suponer, que los créditos existentes se deben, bien al sistema de cesión o arrendamiento de instalaciones para determinadas fases del proceso fabril, o bien al sistema de comercialización de géneros a crédito. Las localidades alejadas de los centros fabriles se corresponden con los principales mercados regionales, generalmente situados en las cabezas del partido judicial de la provincia.

la segunda, que se constituye en 1866 como continuación de la anterior, participa también el sevillano Gregorio Soto. Carmona Badía, X."El atraso industrial de Galicia", pag. 228. 
En cuanto al mercado nacional, hemos diferenciado, según el tipo de producto textil, bien sea através de fibras vegetales (lino y cáñamo), o animales (lana). Las primeras tienen por principales clientes a los gobiernos de la nación (la marina principalmente), y los conventos; aunque esta producción es más propia de las grandes fábricas. Los pequeños talleres, colocan sus productos en las localidades próximas de Navarra, Soria y Rioja, expandiendo el mercado hasta Galicia, las provincias castellanas y andaluzas en el último cuato del siglo, posiblemente siguiendo la estela ambulante y arrieril del paño y el lienzo de las fábricas. En los últimos años del siglo, el mercado alpargatero conocerá un auge en su producción, que le llevará a ofertar sus productos en las grandes exposiciones universales, así como en las grandes capitales de provincia, sin por ello abandonar sus mercados próximos (Navarra principalmente), donde mantendrá su hegemonía.

El mercado pañero tuvo y mantuvo tres zonas nacionales, como son Galicia, Castilla y Andalucía, incluso cuando los productos catalanes tomaron la hegemonía del mercado popular. El paño riojano siempre tuvo como clientela habitual la protagonizada por las clases populares, hacia la que se dirigieron sus arrieros y ambulantes; sólo a partir de 1880 disminuirá el volumen de las cuentas de crédito, no sólo debido a la irrupción de los productos catalanes, sino al descenso de la producción riojana, motivada en parte por la decadencia de su estructura fabril, la cual iría cerrando, hasta configurarse en unos pocos y dinámicos grupos industriales.

Las estrategias observadas por estos pocos grupos industriales, fundamentadas en la pertenencia a un amplio grupo de parentesco, permitirán la consolidación de una amplia red de casas comerciales, integradas en buena medida por parientes o paisanos de dichos parientes; las cuáles, mediante el apoyo crediticio y de préstamo de géneros al fiado, lograrán la permanencia del mercado de géneros pañeros riojanos, en las zonas señaladas como tradicionales de su producción textil. 